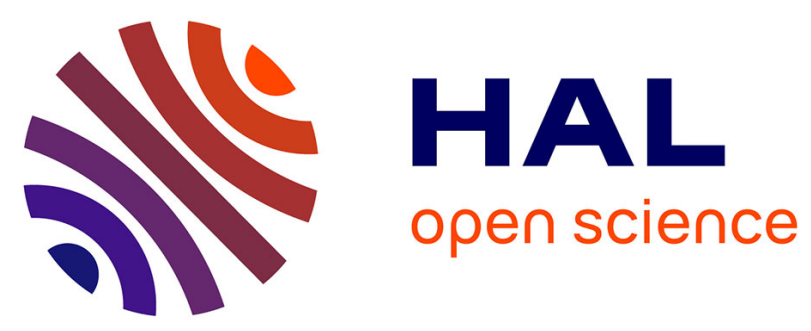

\title{
Assessment of signaling pathway inhibitors and identification of predictive biomarkers in malignant pleural mesothelioma
}

Robin Tranchant, Lisa Quetel, François Montagne, Julien de Wolf, Clément Meiller, Leanne de Koning, Françoise Le Pimpec-Barthes, Jessica

Zucman-Rossi, Marie-Claude Jaurand, Didier Jean

\section{To cite this version:}

Robin Tranchant, Lisa Quetel, François Montagne, Julien de Wolf, Clément Meiller, et al.. Assessment of signaling pathway inhibitors and identification of predictive biomarkers in malignant pleural mesothelioma. Lung Cancer, 2018, 126, pp.15-24. 10.1016/j.lungcan.2018.10.015 . inserm-02478609

\section{HAL Id: inserm-02478609 https://www.hal.inserm.fr/inserm-02478609}

Submitted on 18 Feb 2020

HAL is a multi-disciplinary open access archive for the deposit and dissemination of scientific research documents, whether they are published or not. The documents may come from teaching and research institutions in France or abroad, or from public or private research centers.
L'archive ouverte pluridisciplinaire HAL, est destinée au dépôt et à la diffusion de documents scientifiques de niveau recherche, publiés ou non, émanant des établissements d'enseignement et de recherche français ou étrangers, des laboratoires publics ou privés. 


\section{$\underline{\text { Title }}$}

Assessment of signaling pathway inhibitors and identification of predictive biomarkers in malignant pleural mesothelioma

\section{Authors names and affiliations}

1. Robin Tranchant ${ }^{1,2,3,4,{ }^{*}}$

2. Lisa Quetel $1^{1,2,3,4}$

3. François Montagne $e^{1,2,3,4,5,6, \uparrow}$

4. Julien De Wolf $1,2,3,4, \pm$

5. Clement Meiller $1,2,3,4$

6. Leanne De Koning ${ }^{7}$

7. Françoise Le Pimpec-Barthes s $^{1,2,3,4,8,9}$

8. Jessica Zucman-Rossi ${ }^{1,2,3,4,9}$

9. Marie-Claude Jaurand $d^{1,2,3,4}$

10. Didier Jean ${ }^{1,2,3,4}$

1'Inserm, UMR-1162, Génomique fonctionnelle des tumeurs solides, F-75010, Paris, France.

2Université Paris Descartes, Sorbonne Paris Cité, Labex Immuno-oncology, F-75000, Paris, France.

${ }^{3}$ Université Paris Diderot, Sorbonne Paris Cité, Institut Universitaire d'Hématologie, Paris, F-75010, France.

${ }^{4}$ Université Paris 13, Sorbonne Paris Cité, F-93206, Saint-Denis, France.

${ }^{5}$ Service de Chirurgie Thoracique, Hôpital Calmette - CHRU de Lille, F-59000, Lille, France

${ }^{6}$ Université Droit et Santé Lille 2, F-59000, Lille, France 
${ }^{7}$ Institut Curie, PSL Research University, Translational Research Department, F 75005, Paris, France.

${ }^{8}$ Département de Chirurgie Thoracique, Hôpital Européen Georges Pompidou, F75015, Paris, France.

${ }^{9}$ Assistance Publique-Hôpitaux de Paris, Hôpital Européen Georges Pompidou, F75015, Paris, France.

* Present address: Laboratoire de Biochimie (LBC), ESPCI Paris, PSL Research University, CNRS UMR8231 Chimie Biologie Innovation, Paris, France.

† Present address: Département de Chirurgie générale et thoracique, $\mathrm{CHU}$ de Rouen, F-76000, France.

₹ Present address: Département de Chirurgie Thoracique et Transplantation Pulmonaire, Hôpital Foch, Suresnes, F-92150, France. 


\section{Corresponding author}

Didier JEAN

INSERM UMR-1162

27, rue Juliette Dodu

F-75010 PARIS

FRANCE

Phone: +33 (0)172639350

E-mail address: didier.jean@inserm.fr

\section{Authors' contributions}

MCJ, DJ and JZR designed the study. RT, LQ, FM, JDW, LDK, and CM performed the experiments and acquired the data. RT, LQ, FM, JDW, CM, MCJ and DJ analyzed and interpreted the acquired data. RT, FLB, MCJ, DJ and JZR participated in scientific discussion. RT, MCJ and DJ wrote the manuscript and approved the final version. 


\section{$\underline{\text { Abstract }}$}

\section{Objectives}

Malignant pleural mesothelioma (MPM) is an aggressive tumor with limited therapeutic options, requiring the development of efficient targeted therapies based on molecular phenotype of the tumor and to identify predictive biomarkers of the response.

\section{Materials and Methods}

The effect of inhibitors was investigated by cell viability assessment on primary MPM cell lines established in our laboratory from patient tumors, well characterized at the molecular level. Effects on apoptosis, cell proliferation and viability on MPM growing in multicellular spheroid were also assessed for verteporfin. Gene and protein expression, and gene knockdown by RNA interference were used to define mechanism of inhibition and specific predictive biomarkers.

\section{Results}

Anti-tumor effect of eight major signaling pathways inhibitors involved in mesothelial carcinogenesis was investigated. Three inhibitors were more efficient than cisplatin, the drug used as first-line chemotherapy in patients with MPM: verteporfin, a putative YAP inhibitor, defactinib, a FAK inhibitor and NSC668394, an Ezrin inhibitor. Verteporfin, the most efficient inhibitor, induced cell proliferation arrest and cell death, and is effective on 3D spheroid multicellular model. Verteporfin sensitivity was YAP-independent and related to molecular classification of the tumors. Biomarkers based on gene expression were identified to predict accurately sensitivity to these three inhibitors. 


\section{Conclusion}

Our study shows that drug screening on well-characterized MPM cells allows for the identification of novel potential therapeutic strategies and defining specific biomarkers predictive of the drug response. 


\section{Highlights}

- Three signal pathway inhibitors show higher toxicities than cisplatin: verteporfin, defactinib and NSC668394

- Verteporfin sensitivity is related to molecular classification in subgroups

- Verteporfin inhibits cell viability independently of YAP

- Defactinib sensitivity is related to FAK protein kinase activation

- Predictive biomarkers of inhibitors response were defined based on gene expression

\section{Key words}

Thoracic tumor; Target therapy; Signal pathway; Predictive biomarker; Tumor molecular classification

\section{Classification codes}

No relevant INSPEC codes. 


\section{Introduction}

Malignant pleural mesothelioma (MPM) is a rare tumor principally due to past exposure to asbestos, a carcinogenic natural mineral fiber that induces genomic and genetic alterations [1]. Lack of curative treatment due to resistance to anti-cancer therapies combined with tumor aggressiveness accounts for the poor prognosis associated to MPM. Despite the significant advances in oncotherapy, MPM is still a challenging cancer to treat [2].

MPM tumors are heterogeneous at the molecular level, showing a complex pattern of chromosomal abnormalities and tumor suppressor gene mutations. These alterations result in differential gene expression between MPM tumors, and deregulation of cell signaling pathways specific to each tumor [3], [4]. On the basis of gene expression profiles, we recently defined a robust MPM molecular classification consisting of two groups ( $\mathrm{C} 1$ and $\mathrm{C} 2$ ) with different gene alterations, pathway deregulations, histologic subtypes and survival outcomes [5]. More recently, we identified a new MPM molecular subgroup, $\mathrm{C}^{\mathrm{LN}}$, characterized by inactivating mutations in NF2 and LATS2 tumor suppressor genes, and targetable by mTOR/PI3K/AKT inhibitor [6].

Presently, there is a strong need to develop efficient therapeutic strategies based on the molecular characteristics of each tumor that takes into account the tumor specificity and inter-tumor heterogeneity. Therapies targeting signal pathways are promising in cancer treatment including MPM. However, clinical trials in MPM using targeted therapies have not improved the results of standard cisplatin-pemetrexed chemotherapy until recently with the addition of bevacizumab, an inhibitor of angiogenesis (VEGF) [7]. These disappointing results could be due to the lack of 
consideration of MPM molecular heterogeneity during the clinical trials. The use of existing treatments from other cancers has not showed significant benefit in MPM [8]. It is also likely due to the limited number of relevant preclinical studies investigating potent anti-cancer compounds as most of these preclinical studies were performed using a few number of MPM cell lines not-well characterized at the molecular level.

One of the major issues in targeted therapy is to identify predictive biomarkers of treatment response. Predictive biomarkers based on a gene expression signature are reliable, implementable in clinic and complementary to biomarkers defined by immunohistochemistry or mutation status [9], [10].

The present work focuses on several inhibitors of signal pathways, with the aim to evaluate their therapeutic interest, to determine the correlation between inhibitorsensitivity and MPM molecular phenotype as defined by molecular group (C1, C2 or $\mathrm{C}^{\mathrm{LN}}$ ) and mutational status, and to identify predictive biomarkers of inhibitors sensitivity. 


\section{Materials and methods}

\subsection{Mesothelioma cell cultures}

MPM in culture (33 cases) were primary cell lines established in our laboratory and used in several previous studies, showing their relevance to MPM primary tumors [11], [12], [13], [5], [6]. Cells were grown as previously described and used at low-passage numbers ( $<12$ passages) [14].

\section{2 siRNA-targeted knockdown}

YAP1 and EZR knockdown was performed as previously described by using two different siRNA for each targeted gene (Supplementary Table S1) [6]. Control cells were transfected without siRNA and with two untargeting siRNA (siControl.1 and siControl.2).

\subsection{Inhibitors assays}

MPM cells were seeded in triplicate on 96-well plates (Corning, BoulogneBillancourt, France) at $1 \times 10^{4}$ and $3 \times 10^{4}$ cells/well for non-confluent and confluent conditions, respectively. For spheroid assay, $1 \times 10^{4}$ cells/well were also seeded in triplicate on 96-well Ultra Low Attachment Spheroid Microplate (Falcon \#4520, Corning). Cells were treated for 48 hours with gradient concentrations of inhibitors. All inhibitors were diluted in DMSO except cisplatin, which was diluted in $\mathrm{NaCl} 0.9 \%$ at $0.5 \mathrm{mg} / \mathrm{mL}$. For adherent cells assay, cell viability was quantified by MTS assay (CellTiter 96 AQueous One Solution Cell Proliferation Assay, Promega) using an absorbance reader (FLUOstar Omega, BMG Labtechnologies). For spheroid assay, pictures were taken using a 2.5x objective on a Carl Zeiss Axiocam MRc. Results were obtained from at least two independent experiments. A first screen was realized 
on 20 MPM cell lines representative of the different molecular phenotypes. Some results were discarded because they did not give reproducible results depending on the inhibitor or the cell line. The screen was extended to another cell lines based on the preliminary correlation we observed between inhibitor-sensitivity and MPM molecular phenotype. The overlap between the MPM in culture treated with the inhibitors is shown in the heat map (Fig. S1a).

\subsection{Apoptosis assays}

Apoptosis assays were performed by Annexin $\mathrm{V}$ and propidium iodide (PI) staining as previously described [6].

\subsection{Proliferation assays}

MPM cells were seeded in triplicate on 96-well plates (Corning) at $1 \times 10^{4}$ cells/well. Twenty-four hours after verteporfin treatment, cells were labeled with EdU (A10044, ThermoFisher, Illkirch, France - $10 \mu \mathrm{mol} / \mathrm{L})$ during 24 hours. Cells were fixed with Formalin (HT5012, Sigma-Aldrich, St. Quentin Fallavier, France - 4\%), stained with Hoechst 33342 (H3570, ThermoFisher - $5 \mu \mathrm{g} / \mathrm{mL}$ ) and permeabilized with Triton (X-100, Sigma-Aldrich - 0.3\%). EdU incorporated in DNA was detected by fluorescent-azide coupling reaction using a mix of Alexa Fluor 647 Azide (A10277, ThermoFisher - $3 \mu \mathrm{mol} / \mathrm{L})$ - $\mathrm{CuSO}_{4}$ (35185, VWR, Fontenay-sous-bois, France - 1 mmol/L) - Ascorbic acid (A5960, Sigma-Aldrich - $100 \mathrm{mmol} / \mathrm{L}$ ). Cells were imaged with a high-content imaging device (Operetta CLS, Perkin Elmer, Villebon sur Yvette, France) using a 10x objective with four fields per well captured. Number of nuclei and EdU positive cells were determined using Harmony software (version 4.6, Perkin Elmer). 


\subsection{Protein and mRNA expression analyses}

Preparation of MPM cells lysates, western blot and reverse phase protein array (RPPA) were done as previously described [6], [15]. Preparation of total RNA and gene expression measurement by RT-quantitative PCR were done as previously described [6]. Predefined TaqMan probes (Supplementary Table S1) were chosen from the Thermo Fisher Scientific database (http://www.thermofisher.com). All samples were assayed in duplicate and gene expression was normalized to internal control ribosomal $18 \mathrm{~S}$ relative to the mean expression of the corresponding gene in three normal mesothelial cells in culture or to control cells (DMSO treatment)

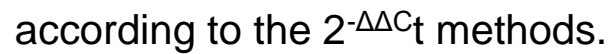

\subsection{Data and statistical analyses}

Graph Pad Prism version 6 software was used to calculate normalized Area Under Curve (AUC) and GI50 of inhibitors assays and to perform the statistical tests: Mann-Whitney test for the whole MPM series data, unpaired t test with or without Welch's correction as appropriate for siRNA or inhibitor assay and rank Spearman test for correlation analysis. $P$-values are shown in the figures as ${ }^{*} P<0.05$, ${ }^{* *} P<$ 0.01 and ${ }^{* *} P<0.001$. 


\section{Results}

\subsection{Screening of pre-selected inhibitors}

Cell viability was measured on 19 to 30 MPM in culture treated with eight signaling pathway inhibitors or cisplatin, the chemotherapy drug used as first-line therapy in patients with MPM. These MPM cell lines were selected according to their molecular phenotypes i.e. molecular group $\left(\mathrm{C} 1, \mathrm{C} 2\right.$ or $\left.\mathrm{C}^{\mathrm{LN}}\right)$ and mutational status to have a sufficient number of MPM cell lines for each molecular characteristic (Supplementary Table S2). Summary of normalized AUC and GI50 calculated from cell viability curves (Fig. S1b and Supplementary Table S3) is shown in Figure 1a. Verteporfin, a YAP/TEAD inhibitor, NSC668394, an Ezrin inhibitor, and defactinib, a FAK inhibitor, show the highest effect on viability. Based on the GI50 and AUC average, but also the profiles of the viability curves obtained on all MPM in culture, these three inhibitors were more efficient than cisplatin (Fig. 1a-b and Fig. S1). Vandetanib, a multi-kinase inhibitor targeting EGFR/VEGFR-2/RET, and PD166866, a FGFR1 inhibitor, have an anti-tumor effect on some cultured MPM, but their overall efficacy is lower than cisplatin. Saracatinib, a Src and Bcr-Abl dual inhibitor, Trametinib, a MEK1/2 inhibitor, and galunisertib, a TGF $\beta$ pathway inhibitor, have no decrease or only a slight decrease in cell viability in most cultured MPM, even at high concentration. Verteporfin, NSC668394 and defactinib remain the most efficient inhibitors even if the analysis is limited to the 13 overlapping cell lines used in the viability assays of all the inhibitors except galunisertib (Fig. S1a and Fig. S2a).

As YAP is regulated by cell-cell contact via Hippo pathway, verteporfin sensitivity was determined on confluent MPM cells (Fig. S1b and Supplementary Table S3). However, the different sensitivities of MPM were not modified under confluent 
conditions, except a slight increase between non confluent and confluent conditions in MPM treated with verteporfin (Fig. S2b-c).

\subsection{Relations between inhibitor sensitivity and molecular phenotype}

We then focused on the three most efficient inhibitors, verteporfin, NSC668394 and defactinib. These inhibitors also showed a high coefficient of variation between MPM for GI50, 91\%, $60 \%$ and $40 \%$ respectively, as compared to $28 \%$ for cisplatin (Fig. S2d), possibly associated to a specific molecular phenotype.

Consequently, we determined whether inhibitor sensitivity of MPM in culture was associated to molecular groups, $\mathrm{C} 1, \mathrm{C} 2$ or $\mathrm{C}^{\mathrm{LN}}$ [5], [6]. We also analyzed the correlation with the mutational status, since all MPM were previously characterized for genetic alterations in key genes of mesothelial carcinogenesis (CDKN2A, CDKN2B, BAP1, NF2, LATS2, TP53 and TERT promoter) [11], [12], [13], [5], [6].

NSC668394 and defactinib sensitivities were not related to molecular classification or mutational profile, including inactivating mutation in NF2 gene or protein expression of Merlin (protein encoded by NF2) as previously described for defactinib (Fig. S3a-e) [16]. In contrast with the two previous inhibitors, we observed an association between verteporfin sensitivity and molecular groups, with MPM of the C1 group being significantly more sensitive to verteporfin than MPM of the C2 group, based on AUC (Fig. 2a, $P=0.01$ ) and GI50 (Fig. 2b, $P=0.03$ ). No link was found with mutational status of NF2 and LATS2 genes, two genes of the Hippo pathway that regulate YAP activity (data not shown). 


\subsection{Effect of verteporfin on cell viability}

To further analyze the verteporfin effect on cell viability, additional experiments were performed on selected verteporfin sensitive and resistant cell lines.

We confirmed the effect of verteporfin on MPM cell viability in a 3D spheroidmodel. This model better mimics some features of solid tumors, such as their spatial architecture. Figure S4 shows two representatives MPM in culture (MPM_38 and MPM_04) of four MPM tested (also including MPM_32 and MPM_16) with variable molecular phenotypes i.e. molecular classification subgroup and LATS2/NF2 mutation status (Supplementary Table S3). In all cases, treatment with verteporfin induced cells detaching from the spheroids and floating in the medium.

To better understand the mechanism of verteporfin toxicity, the percentage of proliferating cells was analyzed by detection of EdU-positive cells in two MPM in culture treated with two concentrations of verteporfin during 48 hours. A decrease of EdU-positive cells number was observed in both cell lines, with a higher decrease in MPM_32, a sensitive MPM than in MPM_37, a resistant MPM (Fig. 2c and Fig. S5a). To determine the induction of apoptosis/necrosis by verteporfin treatment, we used annexin V/propidium iodide staining assay. After treatment with two concentrations of verteporfin during 48 hours, necrotic and apoptotic cells were observed in both cell lines, with $78.4 \%$ and $32.7 \%$ of death cells observed in sensitive and resistant MPM, respectively (Fig. S5b). This result was validated in two other sensitive and two other resistant MPM in culture confirming the higher induction of cell death in sensitive MPM by verteporfin treatment (Fig. 2d).

\subsection{Relation between verteporfin anti-tumor effect and YAP activity}

As verteporfin was described as a YAP/TEAD inhibitor, we first studied its effect 
on YAP activity. Our data show that verteporfin induced significant downregulation of the expression of YAP target genes, CTGF and CYR61 in MPM_32, one of the most verteporfin sensitive cell line (Fig. 3a). We compared the effect of verteporfin treatment and of $Y A P 1$ downregulation using specific siRNA on MPM cell viability in nine MPM in culture. The level of downregulation of YAP1 by siRNA was similar between MPM in culture [6]. YAP1 siRNA-downregulation resulted in variable inhibition of cell viability ranging from $12 \%$ to $45 \%$, but the inhibition levels were not correlated to verteporfin sensitivity (Fig. $3 b$ and 3c). Furthermore, when YAP1 was downregulated by siRNA before verteporfin treatment, verteporfin sensitivity of two MPM in culture was not modified (Fig. 3d).

\subsection{Identification of biomarkers of sensitivity}

To define a specific biomarker to predict verteporfin response in MPM, we considered the genes differentially expressed between $\mathrm{C} 1 / \mathrm{C} 2$ molecular groups as we found a relation between verteporfin sensitivity and molecular groups (Fig. 2a-b). Correlations between mRNA expressions of several of these genes and verteporfin sensitivity are shown in figure 4a. In control, we also compared the verteporfin sensitivity to markers of YAP activity. Contrary to several biomarkers of molecular groups, no significant correlation was found, supporting our previous observation of a YAP-independent anti-tumor effect of verteporfin. The most significant $P$ were obtained with MOK $(r=0.67 ; P=0.0006)$ and $\operatorname{SLC9A3R1}(r=-0.61 ; P=0.001)$, inversely correlated and correlated with verteporfin sensitivity, respectively (Fig. 4bc). We found that the better correlation occurred with $\log _{2}$ ratio MOK/SLC9A3R1 $(M / S)$ and verteporfin sensitivity $(r=0.72 ; P=0.0002)(F i g .4 d)$. This ratio allows to refine the prediction of verteporfin sensitivity. 
For NSC668394, we found a significant correlation with the level of Ezrin gene and protein expression (Fig. 5a-b). However, no correlation was observed with the level of Ezrin-Radixin-Moesin phosphorylation and no alteration of cell viability was detected after downregulation of Ezrin by siRNA in three MPM, highly sensitive to NSC668394 (Gl50: 1.6 to $2.9 \mu \mathrm{mol} / \mathrm{L})$ (Fig. S6a-c).

For defactinib, an inverted tendency was observed when correlations were analyzed between defactinib normalized $A U C$ and FAK protein expression or phosphorylation in all MPM in culture (Fig. $5 c-d$ ), but not with the gene expression of the encoding gene PTK2 (Fig. S7a). The correlation between defactinib normalized AUC and FAK protein expression $(r=-0.59 ; P=0.008)$ or phosphorylation $(r=-$ $0.67 ; P=0.010)$ was significant when only epithelioid MPM (MME) are considered (Fig. 5c-d). FAK phosphorylation is highly correlated to Paxilin phosphorylation in all MPM in culture $(r=0.72 ; P=0.0002)$ and MME $(r=0.64 ; P=0.022)$ (Fig. $5 e)$, suggesting regulation of FAK pathway by integrin signaling pathway. To define a specific biomarker to predict defactinib response in MPM, we analyzed correlations between defactinib normalized AUC and several regulators of integrin pathway: VTN, VCAN and LUM. LUM gene expression shows the strongest correlation with FAK phosphorylation and defactinib sensitivity in all MPM and in MME (Fig. 2f-g, Fig. S7b). 


\section{Discussion}

An important issue in the management of MPM, and in the development of new therapies, is to consider the molecular diversity of tumors between patients. Despite discouraging results in clinical trials, target therapy is still a promising strategy in MPM and is complementary to immunotherapy, which has recently emerged as an effective treatment in MPM [17]. Signaling pathways are attractive targets in the treatment of cancers as major contributors to tumor growth in response to autocrine or paracrine stimuli.

In this study, we make a robust assessment of the anti-tumor potential of eight inhibitors of major signaling pathways deregulated during MPM carcinogenesis by analyzing more than twenty MPM cell lines. We also compared their toxicity to that of cisplatin, the first-line reference treatment in MPM. Concerning cisplatin, our results are consistent with data from the Genomics of Drug Sensitivity in Cancer (GDSC) database (Release 7.0, March 2018, http://www.cancerrxgene.org/), which include also data for two others inhibitors used in this study (trametinib and saracatinib) [18]. GDSC data showed an average AUC of 0.90 (Min - Max: 0.79-0.96) on 15 MPM cell lines compared to an average AUC of 0.93 (Min - Max: 0.76-1.07) observed in our 19 MPM in culture.

The three inhibitors, galunisertib, trametinib and saracatinib show slight effect on MPM cell viability. Galunisertib, a selective ATP-mimetic inhibitor of transforming growth factor beta receptor I (TGF $\beta$ RI), is the only TGF- $\beta$ pathway inhibitor currently used in clinical trials. This pathway, a key regulator of epithelial-mesenchymal transition in tumor cells, is one of the main signal pathways deregulated between our previously identified molecular groups, C1 and C2 [5]. For the first time, we tested 
this inhibitor on MPM cells, and we were not able to show any significant effect on cell viability in vitro, despite the fact that in mouse preclinical models, targeting of TGF $\beta$ pathway inhibits the growth of established MPM tumors [19]. This supports that anti-tumor effect of TGF $\beta$ pathway inhibitors is related to increase anti-tumor immune response rather than a direct effect on tumor cells. Trametinib is a mitogen-activated protein kinase (MEK) inhibitor and several studies described MAPK kinase pathway contribution to MPM carcinogenesis [20]. As for galunisertib, the MPM in culture of our collection are not sensitive to trametinib and a recent study reported similar results [21]. These authors found IC50 higher than $10 \mu \mathrm{mol} / \mathrm{L}$ in 3/4 commercial MPM cell lines. Only MSTO-211H cell line was sensitive to trametinib with an IC50 equal to $0.15 \mu \mathrm{mol} / \mathrm{L}$. Surprisingly, in the GDSC database, 17/19 MPM show an IC50 below $10 \mu \mathrm{mol} / \mathrm{L}$ including one cell line, $\mathrm{NCl}-\mathrm{H} 2452$, which is resistant in Cho et al. study [21]. Saracatinib is an inhibitor of Bcr-Abl tyrosine-kinase and Src family kinases shown to be activated in MPM [22]. To our knowledge, this inhibitor was not investigated previously on MPM and only three MPM cell lines were assayed in the GDSC database, showing a low AUC (0.92). We confirmed that saracatinib exerted very slight effect on MPM viability. Interestingly, dasatinib, an inhibitor that targets the same kinases than saracatinib, also showed a moderate effect on three MPM cell lines [23].

The two inhibitors, PD166866 and vandetanib inhibited viability of some MPM cells, but at high concentration. PD166866 is a selective FGFR1 tyrosine kinase inhibitor, which was suggested as a growth driver of MPM [24]. In our study, no significant effect was found on MPM cells viability, except in two epithelioid MPM cells in culture after treatment by PD166866. At least two studies have already analyzed the anti-tumor effect of PD166866 in MPM, showing also contrasting results 
depending of the MPM cell lines, but a significant in vivo anti-tumor effect in synergy with cisplatin and ionizing radiation in sensitive MPM cell lines [25], [26]. Our results highlight that PD166866 may have a therapeutic interest, only in a small subset of patients. Vandetanib is an anti-angiogenic inhibitor that targets tyrosine kinase activities of three receptors EGFR/VEGFR-2/RET. Vandetanib was assayed in two other studies, but in only two and four different MPM cell lines [27], [28]. Another antiangiogenic inhibitor, bevacizumab, has shown significant improvement of patient survival [7]. It could be interesting to use anti-angiogenic inhibitors in clinical trials that impair viability of tumor cells. Our results indicate that vandetanib is not the best candidate in this perspective, but another anti-angiogenic inhibitor, nintedanib, that showed higher toxicity in 20 MPM cell lines, could be more relevant [29]. However, we should mention that the results of the recent phase 3 clinical trial LUME-Meso (ClinicalTrials.gov Identifier: NCT01907100) associating nintedanib to the combination pemetrexed/cisplatin for the treatment of MPM were disappointing.

NSC668394, defactinib and verteporfin were the more effective inhibitors and demonstrated a stronger effect on viability than cisplatin. It would be interesting to compare also their efficiencies to the cisplatin/pemetrexed combination used as the standard first-line systemic treatment in MPM, even if it could be problematic to compare the efficiency of single compound to combination of compounds from a methodological point of view. No correlation with the molecular phenotype (molecular classification or mutational profile) was found for NSC668394 and defactinib. However, verteporfin sensitivity was strongly linked to the $\mathrm{C} 1$ and $\mathrm{C} 2$ molecular classification we previously defined [5], with MPM from the C1 molecular group being more sensitive than those from C2 group.

We are the first to show an anti-tumor effect of NSC668394 in MPM. This 
inhibitor was developed as an inhibitor of the phosphorylation of Ezrin (EZR gene), an ERM (Ezrin, Radixin and Moesin) protein involved in the organization of specialized cell-membrane domains found in epithelial cells by linking the actin cytoskeleton to multiple membrane-associated proteins [30]. We observed a negative correlation between NSC668394 sensitivity and EZR gene and protein expression. However, the specific and effective inhibition of EZR by siRNA (more than $90 \%$ inhibition observed in three MPM in culture) did not affect cell viability, as shown in Fig. S6a-c, nor migration or cell invasion of three MPM in culture (data not shown). NSC668394 was shown to have a higher affinity for Ezrin than for its two related proteins Moesin or Radixin with an IC50 of 8.1, 59.5 and $35.3 \mu \mathrm{mol} / \mathrm{L}$, respectively [31]. However, we can not exclude that this inhibitor, contrary to siRNA, abrogated phosphorylation of Moesin and Radixin. Further investigations need to be done to understand the mechanism of this inhibitor.

Defactinib is an inhibitor of FAK protein kinase. A synthetic lethality was described with another FAK inhibitor, the VS-4718, in MPM cell lines that lost the expression of merlin protein, encoded by the NF2 gene, one of the most frequently mutated tumor suppressor genes in MPM [16]. In our study, we tested defactinib rather than VS-4718 as defactinib is used in several MPM clinical trials (ClinicalTrials.gov Identifier: NCT01870609, NCT02004028 and NCT02758587). Despite the clinical trial NCT01870609 was stopped during recruitment when no difference in defactinib versus placebo were observed, the two other clinical trials are still ongoing. The two last clinical trials are still ongoing. We did not find a significant correlation between the protein expression or the mutational status of NF2 gene and defactinib sensitivity. A lack of significant association between merlin expression and VS-4718 sensitivity was also reported in a recent study by Kato et al., contrary to 
what was previously suggested by Shapiro et al. [16], [32]. Defactinib sensitivity is also not related to E-cadherin ( $\mathrm{CDH} 1$ gene) gene and protein expression in NF2mutated MPM as suggested by Kato et al. (Fig. S7c-d) [32]. However, our results demonstrated that defactinib sensitivity is strongly correlated to FAK activity especially in epithelioid MPM.

Verteporfin was found to inhibit YAP transcription cofactor activity by disrupting YAP/TEAD complex without light activation [33]. This transcription cofactor has an oncogenic role by regulating cell proliferation in MPM [34]. Verteporfin is a FDA approved molecule clinically used in photodynamic therapy for neovascular macular degeneration [35], and was tested in several clinical trials evaluating photodynamic therapy for cancer treatment. Our results show the toxicity of verteporfin assessed by cell viability on 25 MPM and confirmed previous observation on 5 MPM commercial cell lines [36]. We have demonstrated that verteporfin induces cell proliferation arrest and cell death, and is effective in a 3D model of spheroid multicellular. In vivo inhibition of tumor growth by verteporfin was also demonstrated by Zhang et al. [36]. These data support the interest of verteporfin as an anti-cancer molecule, not only as a photosensitizing agent in MPM treatment.

In our study, we observed that verteporfin inhibited YAP activity, in agreement with the studies of Zhang et al. who showed downregulation of CTGF expression, and further inhibition of YAP expression and TEAD-dependent promoter activity in three verteporfin treated MPM cell lines [36]. However, the authors did not compare the inhibition of MPM cell viability between verteporfin treatment and YAP inhibition by siRNA. Our experiment showed that the effect of YAP1 inactivation by siRNA on cell proliferation varies between MPM in culture and did not correlate with verteporfin sensitivity, and that the proliferation of verteporfin sensitive MPM cells was not 
modified after inhibition of YAP1. These results suggest that verteporfin anti-tumor effect is independent of YAP activity, a result previously reported in colorectal and endometrial cancer cells [37], [38]. Verteporfin toxicity could be related to other mechanisms such as the formation of high molecular weight protein complexes that inhibit autophagy machinery [37].

A common feature of NSC668394, defactinib and verteporfin is the variability of MPM cells response to the inhibitors. The occurrences of sensitive and resistant MPM cell lines lead us to identify specific biomarkers to predict the MPM cells response. Biomarkers based on gene expression are accurate, easy to use and implementable in clinic. NSC668394 anti-tumor effect could be predicted by EZR gene expression. Since defactinib sensitivity was correlated to FAK activity, which relied on Paxilin activation in MPM, we focused on regulators of integrin pathway such as lumican, encoded by LUM gene, which activates FAK pathway in melanoma and gastric cancer cells [39], [40]. LUM gene expression was the best predictor for defactinib sensitivity. Concerning verteporfin sensitivity, significantly related to MPM molecular classification, analysis of discriminant biomarkers between $\mathrm{C} 1$ and $\mathrm{C} 2$ group emphasizes two genes $M O K$ and SLC9A3R1 and the better predictor for verteporfin sensitivity was the ratio between these two genes. MOK is a member of the MAP kinase family that we previously described as a potential biomarker of one molecular subgroup $\mathrm{C} 2{ }^{\mathrm{LN}}$ [6], [41]. SLC9A3R1 is the most deregulated gene between C1 and C2 molecular groups [5]. It encodes the protein EBP50/NHERF, which is involved in actin anchoring mechanism to cell membrane and in different signaling regulatory pathways [30]. It is obvious that these predictive biomarkers will need to be validated on patient tumor samples from clinical trials with these inhibitors. They can nevertheless be informative for a first selection of patients in clinical trials with 
these inhibitors. 


\section{Conclusions}

We identified three inhibitors that are more efficient than cisplatin treatment in MPM cells. Verteporfin sensitivity is linked to the molecular phenotype, more precisely to the $\mathrm{C} 1$ and $\mathrm{C} 2$ molecular classification, and could be a potent anti-cancer drug for MPM of the C1 group. We identified biomarkers based on genes expression, which could accurately predict sensitivity of these three inhibitors in MPM. 


\section{Conflicts of Interest}

The authors declare no potential conflicts of interest.

\section{Acknowledgments}

The authors thank the members of the IUH technological platform for their help with flow cytometry (Niclas Setterblad, Christelle Doliger and Sophie Duchez). Institut Curie RPPA platform for acquisition of RPPA data (Aurélie Cartier, Bérengère Ouine and Audrey Criqui) and Institut Curie bioinformatics platform for bioinformatics support (Patrick Poullet, Stéphane Liva and Philippe Hupé).

\section{Funding}

This work was supported by INSERM, the Fondation ARC pour la recherche sur le cancer, the Ligue Contre le Cancer (lle de France committee), the Chancellerie des Universités de Paris (Legs POIX). LQ and RT were supported by a PhD scholarship from Cancéropôle Région Île-de-France and French Ministry of Higher Education and Research, respectively. FM and JDW were supported both by a grant from Société Française de Chirurgie - Thoracique et Cardiovasculaire (SFCTV), and by grants from the Institut thématique multi-organismes (ITMO) Cancer (Plan Cancer 2014-2019) and Fondation ARC pour la recherche sur le cancer, respectively. The group is supported by the Labex Oncolmmunology (investissement d'avenir), Coup d'Elan de la Fondation Bettencourt-Shueller, the SIRIC CARPEM, the Institut thématique multi-organismes (ITMO) Cancer (Plan Cancer 2014-2019) and Cancéropôle Île-de-France. 


\section{$\underline{\text { References }}$}

[1] S.X. Huang, M.C. Jaurand, D.W. Kamp, J. Whysner, T.K. Hei, Role of mutagenicity in asbestos fiberinduced carcinogenicity and other diseases, J Toxicol Environ Health B Crit Rev 14(1-4) (2011) 179245.

[2] L. Mutti, T. Peikert, B.W.S. Robinson, A. Scherpereel, A.S. Tsao, M. de Perrot, G.A. Woodard, D.M. Jablons, J. Wiens, F.R. Hirsch, H. Yang, M. Carbone, A. Thomas, R. Hassan, State of the Art: Concise Review Scientific Advances and New Frontiers in Mesothelioma Therapeutics, J Thorac Oncol (2018).

[3] M.C. Jaurand, D. Jean, Biomolecular Pathways and Malignant Pleural Mesothelioma, in: C.T. Mineo (Ed.), Malignant Pleural Mesothelioma: Present Status and Future Directions, Bentham Science Publishers Ltd, Sharjah, UAE, 2016, pp. 169-192.

[4] R. Bueno, E.W. Stawiski, L.D. Goldstein, S. Durinck, A. De Rienzo, Z. Modrusan, F. Gnad, T.T. Nguyen, B.S. Jaiswal, L.R. Chirieac, D. Sciaranghella, N. Dao, C.E. Gustafson, K.J. Munir, J.A. Hackney, A. Chaudhuri, R. Gupta, J. Guillory, K. Toy, C. Ha, Y.J. Chen, J. Stinson, S. Chaudhuri, N. Zhang, T.D. Wu, D.J. Sugarbaker, F.J. de Sauvage, W.G. Richards, S. Seshagiri, Comprehensive genomic analysis of malignant pleural mesothelioma identifies recurrent mutations, gene fusions and splicing alterations, Nature genetics 48(4) (2016) 407-16.

[5] A. de Reynies, M.C. Jaurand, A. Renier, G. Couchy, I. Hysi, N. Elarouci, F. Galateau-Salle, M.C. Copin, P. Hofman, A. Cazes, P. Andujar, S. Imbeaud, F. Petel, J.C. Pairon, F. Le Pimpec-Barthes, J. Zucman-Rossi, D. Jean, Molecular classification of malignant pleural mesothelioma: identification of a poor prognosis subgroup linked to the epithelial-to-mesenchymal transition, Clin Cancer Res 20(5) (2014) 1323-34.

[6] R. Tranchant, L. Quetel, A. Tallet, C. Meiller, A. Renier, L. de Koning, A. de Reynies, F. Le PimpecBarthes, J. Zucman-Rossi, M.C. Jaurand, D. Jean, Co-occurring mutations of tumor suppressor genes, LATS2 and NF2, in malignant pleural mesothelioma, Clin Cancer Res 23(12) (2017) 3191-3202.

[7] G. Zalcman, J. Mazieres, J. Margery, L. Greillier, C. Audigier-Valette, D. Moro-Sibilot, O. Molinier, R. Corre, I. Monnet, V. Gounant, F. Riviere, H. Janicot, R. Gervais, C. Locher, B. Milleron, Q. Tran, M.P. 
Lebitasy, F. Morin, C. Creveuil, J.J. Parienti, A. Scherpereel, French Cooperative Thoracic Intergroup, Bevacizumab for newly diagnosed pleural mesothelioma in the Mesothelioma Avastin Cisplatin Pemetrexed Study (MAPS): a randomised, controlled, open-label, phase 3 trial, Lancet 387(10026) (2016) 1405-14.

[8] A. Guazzelli, E. Bakker, K. Tian, C. Demonacos, M. Krstic-Demonacos, L. Mutti, Promising investigational drug candidates in phase I and phase II clinical trials for mesothelioma, Expert Opin Investig Drugs 26(8) (2017) 933-944.

[9] N.P. Tobin, T. Foukakis, L. De Petris, J. Bergh, The importance of molecular markers for diagnosis and selection of targeted treatments in patients with cancer, Journal of Internal Medicine 278(6) (2015) 545-570.

[10] T.R. Samatov, V.V. Galatenko, A. Block, M.Y. Shkurnikov, A.G. Tonevitsky, U. Schumacher, Novel biomarkers in cancer: The whole is greater than the sum of its parts, Seminars in Cancer Biology 45 (2017) 50-57.

[11] P. Andujar, J.C. Pairon, A. Renier, A. Descatha, I. Hysi, I. Abd-Alsamad, M.A. Billon-Galland, H. Blons, B. Clin, C. Danel, D. Debrosse, F. Galateau-Salle, B. Housset, P. Laurent-Puig, F. Le PimpecBarthes, M. Letourneux, I. Monnet, J.F. Regnard, P. Validire, J. Zucman-Rossi, M.C. Jaurand, D. Jean, Differential mutation profiles and similar intronic TP53 polymorphisms in asbestos-related lung cancer and pleural mesothelioma, Mutagenesis 28(3) (2013) 323-31.

[12] A. Tallet, J.C. Nault, A. Renier, I. Hysi, F. Galateau-Salle, A. Cazes, M.C. Copin, P. Hofman, P. Andujar, F. Le Pimpec-Barthes, J. Zucman-Rossi, M.C. Jaurand, D. Jean, Overexpression and promoter mutation of the TERT gene in malignant pleural mesothelioma, Oncogene 33(28) (2014) 3748-52.

[13] D. Jean, E. Thomas, E. Manie, A. Renier, A. de Reynies, C. Lecomte, P. Andujar, J. Fleury-Feith, F. Galateau-Salle, M. Giovannini, J. Zucman-Rossi, M.H. Stern, M.C. Jaurand, Syntenic Relationships between Genomic Profiles of Fiber-Induced Murine and Human Malignant Mesothelioma, Am J Pathol 178(2) (2011) 881-94. 
[14] L. Zeng, A. Buard, I. Monnet, C. Boutin, J. Fleury, L. Saint-Etienne, P. Brochard, J. Bignon, M.C. Jaurand, In vitro effects of recombinant human interferon gamma on human mesothelioma cell lines, Int J Cancer 55(3) (1993) 515-20.

[15] S. Rondeau, S. Vacher, L. De Koning, A. Briaux, A. Schnitzler, W. Chemlali, C. Callens, R. Lidereau, I. Bièche, ATM has a major role in the double-strand break repair pathway dysregulation in sporadic breast carcinomas and is an independent prognostic marker at both mRNA and protein levels, British Journal of Cancer 112(6) (2015) 1059-1066.

[16] I.M. Shapiro, V.N. Kolev, C.M. Vidal, Y. Kadariya, J.E. Ring, Q. Wright, D.T. Weaver, C. Menges, M. Padval, A.I. McClatchey, Q. Xu, J.R. Testa, J.A. Pachter, Merlin deficiency predicts FAK inhibitor sensitivity: a synthetic lethal relationship, Science translational medicine 6(237) (2014) 237-68.

[17] A. Scherpereel, F. Wallyn, S.M. Albelda, C. Munck, Novel therapies for malignant pleural mesothelioma, Lancet Oncol 19(3) (2018) e161-e172.

[18] W. Yang, J. Soares, P. Greninger, E.J. Edelman, H. Lightfoot, S. Forbes, N. Bindal, D. Beare, J.A. Smith, I.R. Thompson, S. Ramaswamy, P.A. Futreal, D.A. Haber, M.R. Stratton, C. Benes, U. McDermott, M.J. Garnett, Genomics of Drug Sensitivity in Cancer (GDSC): a resource for therapeutic biomarker discovery in cancer cells, Nucleic Acids Res 41(Database issue) (2013) D955-61.

[19] E. Suzuki, S. Kim, H.-K. Cheung, M.J. Corbley, X. Zhang, L. Sun, F. Shan, J. Singh, W.-C. Lee, S.M. Albelda, L.E. Ling, A Novel Small-Molecule Inhibitor of Transforming Growth Factor $\beta$ Type I Receptor Kinase (SM16) Inhibits Murine Mesothelioma Tumor Growth In vivo and Prevents Tumor Recurrence after Surgical Resection, Cancer Research 67(5) (2007) 2351-2359.

[20] D. Jean, J. Daubriac, F. Le Pimpec-Barthes, F. Galateau-Salle, M.C. Jaurand, Molecular changes in mesothelioma with an impact on prognosis and treatment, Archives of pathology \& laboratory medicine 136(3) (2012) 277-93.

[21] H. Cho, S. Matsumoto, Y. Fujita, A. Kuroda, T. Menju, M. Sonobe, N. Kondo, I. Torii, T. Nakano, P.N. Lara, D.R. Gandara, H. Date, S. Hasegawa, Trametinib plus 4-Methylumbelliferone Exhibits Antitumor Effects by ERK Blockade and CD44 Downregulation and Affects PD-1 and PD-L1 in 
Malignant Pleural Mesothelioma, Journal of Thoracic Oncology: Official Publication of the International Association for the Study of Lung Cancer 12(3) (2017) 477-490.

[22] C.W. Menges, Y. Chen, B.T. Mossman, J. Chernoff, A.T. Yeung, J.R. Testa, A Phosphotyrosine Proteomic Screen Identifies Multiple Tyrosine Kinase Signaling Pathways Aberrantly Activated in Malignant Mesothelioma, Genes Cancer 1(5) (2010) 493-505.

[23] V. Monica, M. Lo lacono, E. Bracco, S. Busso, L. Di Blasio, L. Primo, B. Peracino, M. Papotti, G. Scagliotti, Dasatinib modulates sensitivity to pemetrexed in malignant pleural mesothelioma cell lines, Oncotarget 7(47) (2016) 76577-76589.

[24] L.A. Marek, T.K. Hinz, A. von Mässenhausen, K.A. Olszewski, E.K. Kleczko, D. Boehm, M.C. Weiser-Evans, R.A. Nemenoff, H. Hoffmann, A. Warth, J.M. Gozgit, S. Perner, L.E. Heasley, Nonamplified FGFR1 is a growth driver in malignant pleural mesothelioma, Molecular cancer research: MCR 12(10) (2014) 1460-1469.

[25] K. Schelch, M.A. Hoda, T. Klikovits, J. Münzker, B. Ghanim, C. Wagner, T. Garay, V. Laszlo, U. Setinek, B. Dome, M. Filipits, C. Pirker, P. Heffeter, E. Selzer, J. Tovari, S. Torok, I. Kenessey, K. Holzmann, B. Grasl-Kraupp, B. Marian, W. Klepetko, W. Berger, B. Hegedus, M. Grusch, Fibroblast growth factor receptor inhibition is active against mesothelioma and synergizes with radio- and chemotherapy, American journal of respiratory and critical care medicine 190(7) (2014) 763-772.

[26] K. Schelch, M.B. Kirschner, M. Williams, Y.Y. Cheng, N. van Zandwijk, M. Grusch, G. Reid, A link between the fibroblast growth factor axis and the miR-16 family reveals potential new treatment combinations in mesothelioma, Molecular Oncology 12(1) (2018) 58-73.

[27] E. Giovannetti, P.A. Zucali, Y.G. Assaraf, L.G. Leon, K. Smid, C. Alecci, F. Giancola, A. Destro, L. Gianoncelli, E. Lorenzi, M. Roncalli, A. Santoro, G.J. Peters, Preclinical emergence of vandetanib as a potent antitumour agent in mesothelioma: molecular mechanisms underlying its synergistic interaction with pemetrexed and carboplatin, British Journal of Cancer 105(10) (2011) 1542-1553.

[28] M. Sayan, A. Shukla, M.B. MacPherson, S.L. Macura, J.M. Hillegass, T.N. Perkins, J.K. Thompson, S.L. Beuschel, J.M. Miller, B.T. Mossman, Extracellular signal-regulated kinase 5 and cyclic AMP 
response element binding protein are novel pathways inhibited by vandetanib (ZD6474) and doxorubicin in mesotheliomas, American journal of respiratory cell and molecular biology 51(5) (2014) 595-603.

[29] V. Laszlo, Z. Valko, I. Kovacs, J. Ozsvar, M.A. Hoda, T. Klikovits, D. Lakatos, A. Czirok, T. Garay, A. Stiglbauer, T.H. Helbich, M. Gröger, J. Tovari, W. Klepetko, C. Pirker, M. Grusch, W. Berger, F. Hilberg, B. Hegedus, B. Dome, Nintedanib Is Active in Malignant Pleural Mesothelioma Cell Models and Inhibits Angiogenesis and Tumor Growth In Vivo, Clinical Cancer Research: An Official Journal of the American Association for Cancer Research (2018).

[30] J. Vaquero, T.H. Nguyen Ho-Bouldoires, A. Claperon, L. Fouassier, Role of the PDZ-scaffold protein NHERF1/EBP50 in cancer biology: from signaling regulation to clinical relevance, Oncogene 36(22) (2017) 3067-3079.

[31] G. Bulut, S.-H. Hong, K. Chen, E.M. Beauchamp, S. Rahim, G.W. Kosturko, E. Glasgow, S. Dakshanamurthy, H.-S. Lee, I. Daar, J.A. Toretsky, C. Khanna, A. Uren, Small molecule inhibitors of ezrin inhibit the invasive phenotype of osteosarcoma cells, Oncogene 31(3) (2012) 269-281.

[32] T. Kato, T. Sato, K. Yokoi, Y. Sekido, E-cadherin expression is correlated with focal adhesion kinase inhibitor resistance in Merlin-negative malignant mesothelioma cells, Oncogene 36(39) (2017) $5522-5531$.

[33] Y. Liu-Chittenden, B. Huang, J.S. Shim, Q. Chen, S.J. Lee, R.A. Anders, J.O. Liu, D. Pan, Genetic and pharmacological disruption of the TEAD-YAP complex suppresses the oncogenic activity of YAP, Genes Dev 26(12) (2012) 1300-5.

[34] T. Mizuno, H. Murakami, M. Fujii, F. Ishiguro, I. Tanaka, Y. Kondo, S. Akatsuka, S. Toyokuni, K. Yokoi, H. Osada, Y. Sekido, YAP induces malignant mesothelioma cell proliferation by upregulating transcription of cell cycle-promoting genes, Oncogene 31(49) (2012) 5117-22.

[35] J.W. Miller, U. Schmidt-Erfurth, M. Sickenberg, C.J. Pournaras, H. Laqua, I. Barbazetto, L. Zografos, B. Piguet, G. Donati, A.M. Lane, R. Birngruber, H. van den Berg, A. Strong, U. Manjuris, T. Gray, M. Fsadni, N.M. Bressler, E.S. Gragoudas, Photodynamic therapy with verteporfin for choroidal 
neovascularization caused by age-related macular degeneration: results of a single treatment in a phase 1 and 2 study, Arch Ophthalmol 117(9) (1999) 1161-73.

[36] W.Q. Zhang, Y.Y. Dai, P.C. Hsu, H. Wang, L. Cheng, Y.L. Yang, Y.C. Wang, Z.D. Xu, S. Liu, G. Chan, B. Hu, H. Li, D.M. Jablons, L. You, Targeting YAP in malignant pleural mesothelioma, J Cell Mol Med $21(11)(2017)$ 2663-2676.

[37] X. Zhang, N. Tang, A.K. Rishi, H.I. Pass, A. Wali, Methylation profile landscape in mesothelioma: possible implications in early detection, disease progression, and therapeutic options, Methods Mol Biol 1238 (2015) 235-47.

[38] V.R. Dasari, V. Mazack, W. Feng, J. Nash, D.J. Carey, R. Gogoi, Verteporfin exhibits YAPindependent anti-proliferative and cytotoxic effects in endometrial cancer cells, Oncotarget $8(17)$ (2017) 28628-28640.

[39] C. Zeltz, S. Brézillon, J. Käpylä, J.A. Eble, H. Bobichon, C. Terryn, C. Perreau, C.M. Franz, J. Heino, F.-X. Maquart, Y. Wegrowski, Lumican inhibits cell migration through $\alpha 2 \beta 1$ integrin, Experimental Cell Research 316(17) (2010) 2922-2931.

[40] X. Wang, Q. Zhou, Z. Yu, X. Wu, X. Chen, J. Li, C. Li, M. Yan, Z. Zhu, B. Liu, L. Su, Cancer-associated fibroblast-derived Lumican promotes gastric cancer progression via the integrin $\beta 1$-FAK signaling pathway, International Journal of Cancer 141(5) (2017) 998-1010.

[41] Y. Miyata, M. Akashi, E. Nishida, Molecular cloning and characterization of a novel member of the MAP kinase superfamily, Genes to Cells: Devoted to Molecular \& Cellular Mechanisms 4(5) (1999) 299-309. 


\section{Legends of figures}

Figure 1. Screening of signaling pathway inhibitors

(a) Summary of normalized AUC and GI50 calculated using Graph Pad Prism (version 6) and obtained on 19 to 30 MPM in culture was shown. Cell viability was determined in the presence of a gradient concentration of each inhibitor by MTS assay for each MPM in culture in at least two independent experiments. (b) Boxplots show normalized AUC of signaling pathway inhibitors and cisplatin calculated on all MPM in culture for each inhibitor.

Figure 2. Relations between inhibitor sensitivity and molecular phenotype and characterization of verteporfin anti-tumor effect

(a-b) Boxplots shows verteporfin normalized AUC (a) or GI50 (b) of 23 MPM in culture according to their belonging to $\mathrm{C} 1$ and $\mathrm{C} 2$ molecular groups. (c) MPM_32, a verteporfin sensitive MPM, and MPM_37, a resistant MPM, were treated with $0.1 \%$ DMSO, 0.5 or $1 \mu \mathrm{mol} / \mathrm{L}$ of verteporfin for 48 hours. MPM cells were stained with Hoescht 33342 and EdU incorporated in DNA was detected by fluorescent-azide coupling. The histogram shows the percentage means $\pm S D$ of EdU-positive cells of two independent experiments for each MPM. (d) Three verteporfin sensitive MPM (MPM_12, MPM_15 and MPM_32) and three resistant MPM (MPM_04, MPM_29 and MPM_37) were treated with $0.1 \%$ DMSO or $1 \mu \mathrm{mol} / \mathrm{L}$ of verteporfin for 48 hours. MPM cells were stained with Annexin V-Alexa Fluor 488 and propidium iodide. Early apoptosis, late apoptosis and necrosis were determined using flow cytometry. The histogram shows the percentage means \pm SD of necrotic and apoptotic cells. 


\section{Figure 3. Relation between verteporfin anti-tumor effect and YAP}

(a) MPM_32, a verteporfin sensitive MPM, was treated with $0.1 \%$ DMSO or $1 \mu \mathrm{mol} / \mathrm{L}$ of verteporfin for 24 hours. mRNA expression of YAP target genes (CTGF and CYR61) was measured by qRT-PCR. The histogram shows the mean of $2^{-\Delta \Delta C t} \pm S D$ of two independent experiments. (b-c) Nine MPM in culture were transfected with siControl and siYAP1, two different siRNAs for each, and proliferation was quantified by MTS assay 96 hours after siRNA transfection. Proliferation of siYAP1 transfected cells was normalized to proliferation of siControl transfected cells (black bars). Verteporfin normalized AUC (white bars) (b) or GI50 (white and striped bars) (c) of each MPM in culture were also represented. The histogram shows means \pm SD. (d) MPM_15, a verteporfin sensitive MPM, and MPM_04, a resistant MPM, were untransfected or transfected with siControl (siControl.1 or siControl.2) and siYAP1 (siYAP1.1 or siYAP1.2) and then cells were treated with a gradient concentration of verteporfin during 48 hours. The upper diagram describes the schedule of the experiment. The cell viability percent was determined by a MTS assay for the five different conditions per cell line. The means of the cell viability percents were calculated for cells transfected with both siControl or with both siYAP1. Cell viability curves are shown: plain curves with round dots represent untransfected MPM; dot curves with square dots siControl transfected MPM; dash curves with triangle dots siYAP1 transfected MPM.

\section{Figure 4. Identification of a predictive biomarker for verteporfin sensitivity}

(a) Correlation analyzes between verteporfin normalized AUC and gene expression of several biomarkers. Histogram shows the $P$-values $(-\log 10)$. Black bars are for gene expression of biomarkers of $\mathrm{C} 1$ and $\mathrm{C} 2$ molecular groups (20 most deregulated 
genes) and the biomarker of the $\mathrm{C} 2^{\mathrm{LN}}$ subgroup (MOK) [5], [6]. White bars are for gene expression of YAP1 and YAP1 target genes (CTGF and CYR61), YAP protein expression and YAP level activity based on the ratio phospho-YAP/YAP. (b-d) Correlation curves between verteporfin normalized AUC and gene expression of MOK (b), SLC9A3R1 (c) and ratio $\log _{2} M O K / S L C 9 A 3 R 1$ (d). Each point represents the mean of the normalized $A U C \pm S D$ of two independent experiments for each MPM. Close circles represent MPM of the C1 molecular group and open circles MPM of the $\mathrm{C} 2$ molecular group.

Figure 5. Identification of predictive biomarkers for NSC668394 and defactinib sensitivities

(a-b) Correlation were performed between NSC668394 normalized AUC and EZR mRNA expression (a) and Ezrin protein expression (b). (c-g) Correlations were performed in all MPM and MME between defactinib normalized AUC and FAK protein expression (c) or phosphorylation (d) or LUM gene expression (e), and between FAK phosphorylation and Paxillin phosphorylation (f) or LUM gene expression (g). Each point represents the mean of the normalized AUC $\pm S D$ of two independent experiments for each MPM. Close circles represent MME and open circles other MPM. 


\section{Figure 1}

a

\begin{tabular}{ccccccc} 
& & & \multicolumn{2}{c}{ Normalized AUC } & \multicolumn{2}{c}{ Gl50 $(\boldsymbol{\mu m o l} / \mathbf{L})$} \\
\cline { 5 - 7 } Molecular inhibitors & Targets & $\begin{array}{c}\text { Number of } \\
\text { MPM in culture }\end{array}$ & Average & Min - Max & Average & Min - Max \\
\hline Verteporfin (Visudyne) & YAP/TEAD association & 25 & 0.70 & $0.45-0.97$ & 1.66 & $0.20-5.85$ \\
NSC668394 & Ezrin & 23 & 0.83 & $0.56-1.06$ & 4.86 & $0.51-10$ \\
Defactinib (VS-6063) & FAK & 29 & 0.85 & $0.69-0.99$ & 7.11 & $1.16-10$ \\
Cisplatin & DNA replication & 19 & 0.93 & $0.76-1.07$ & 7.11 & $3.26-10$ \\
Vandetanib (ZD6474) & VEGFR tyrosine kinase & 24 & 0.92 & $0.66-1.19$ & 8.47 & $2.44-10$ \\
PD-166866 & FGFR1 & 24 & 0.94 & $0.73-1.12$ & 9.18 & $0.13-10$ \\
Saracatinib (AZD0530) & Src tyrosine kinase and Bcr-Abl & 23 & 0.89 & $0.72-1.09$ & 9.77 & $6.90-10$ \\
Trametinib (GSK1120212) & MEK1/2 & 23 & 0.95 & $0.75-1.12$ & $>10$ & $>10$ \\
Galunisertib (LY2157299) & TGFBR1 & 17 & 0.99 & $0.80-1.15$ & $>10$ & $>10$ \\
\hline
\end{tabular}

b

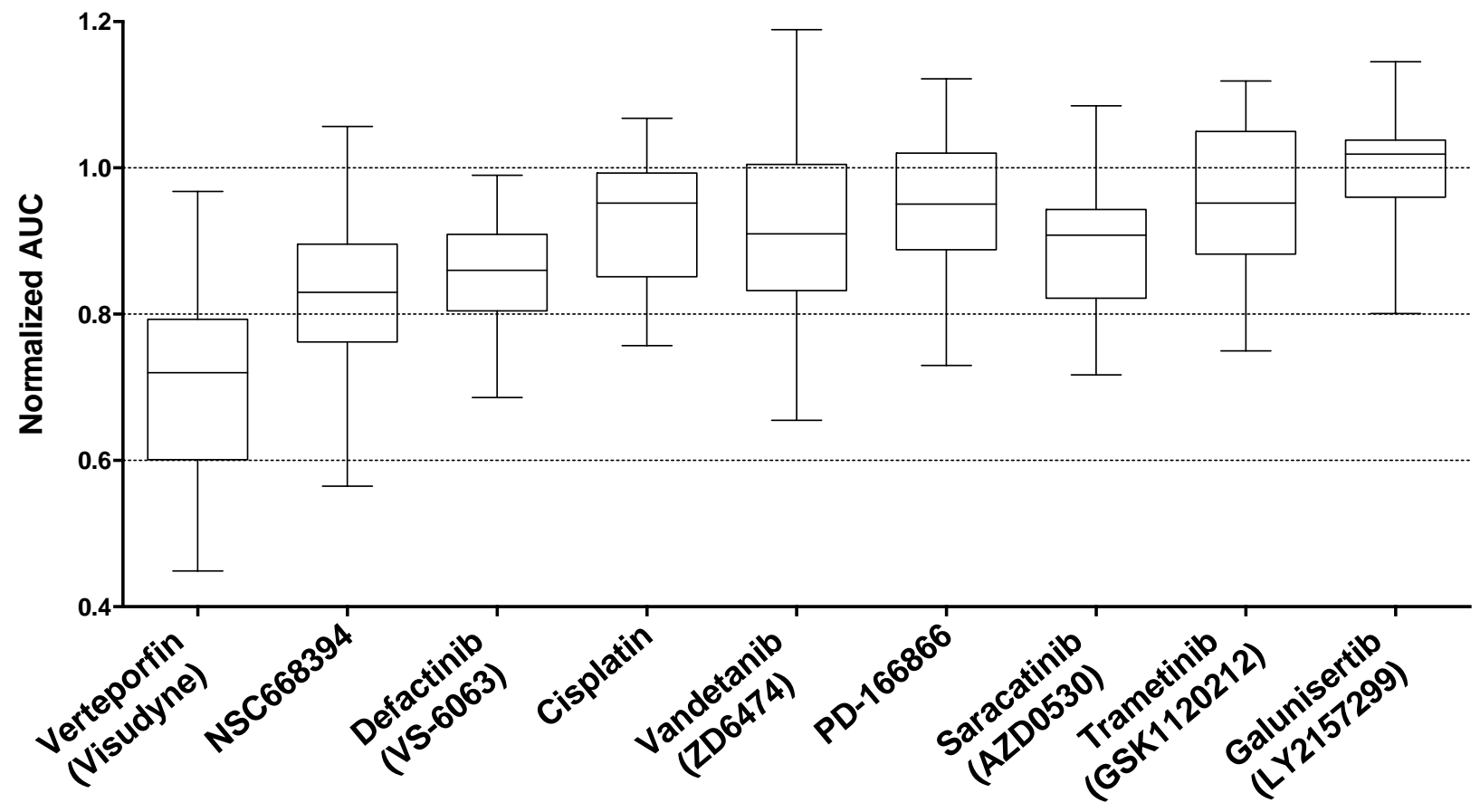


Figure 2

a

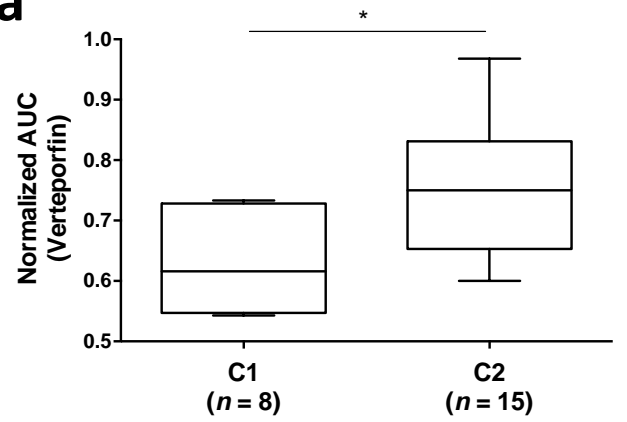

C

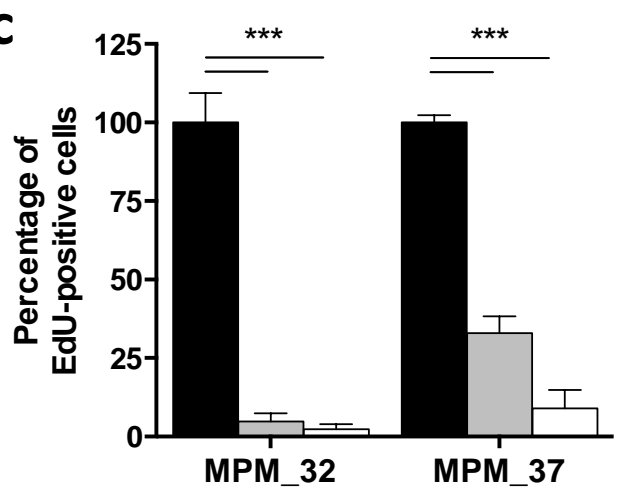

D DMSO $\square 0.5 \mu \mathrm{mol} / \mathrm{L} \square 1 \mu \mathrm{mol} / \mathrm{L}$ b

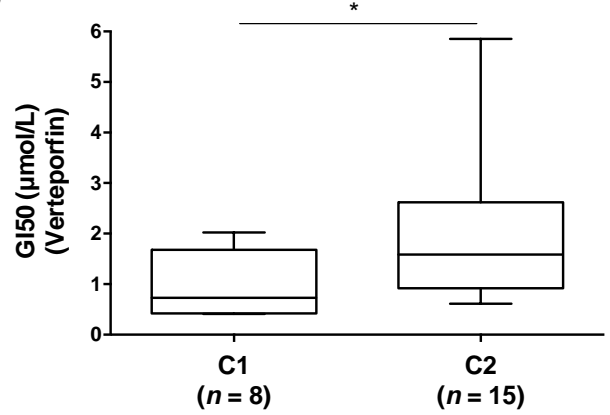

d

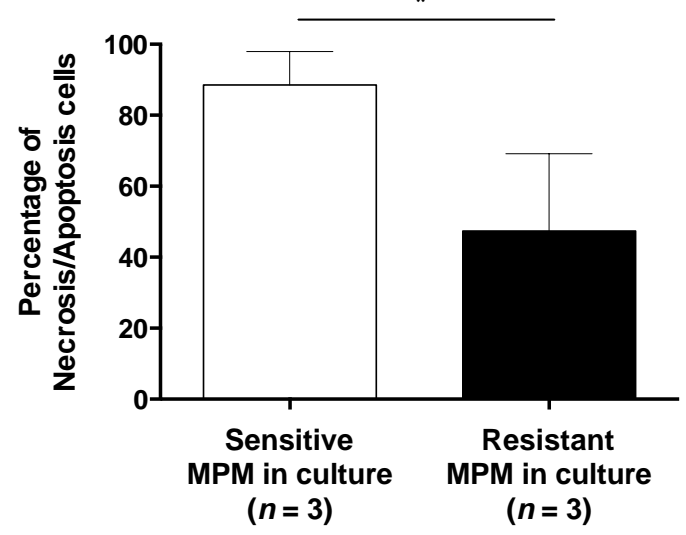


a

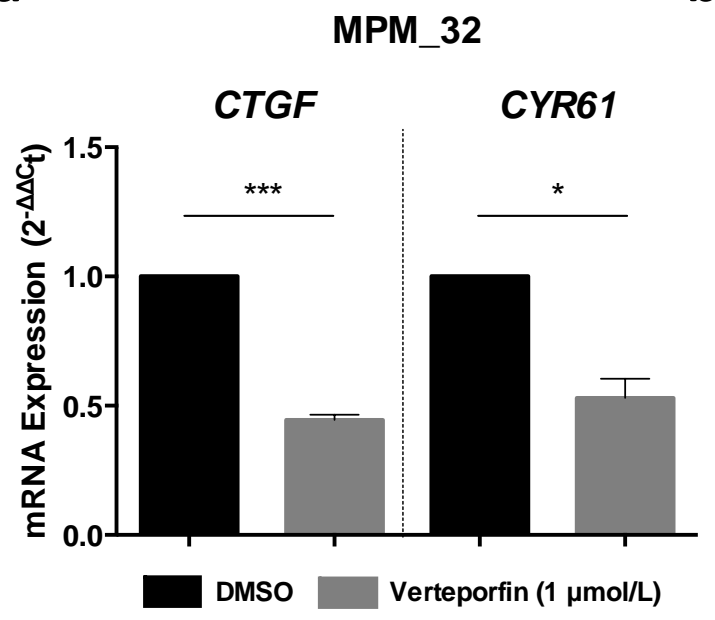

b

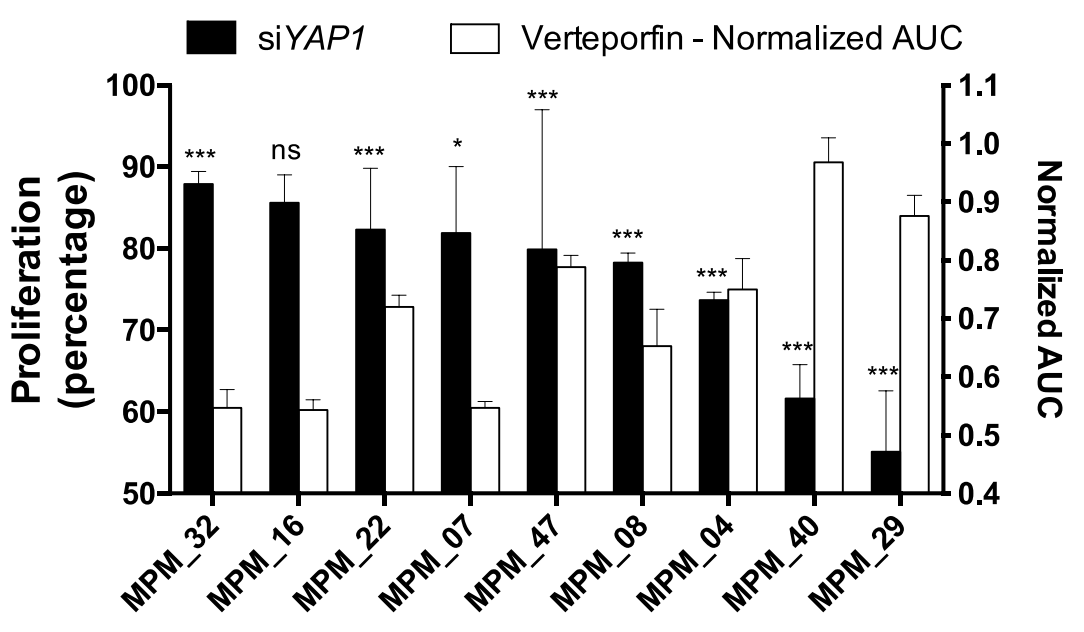

C

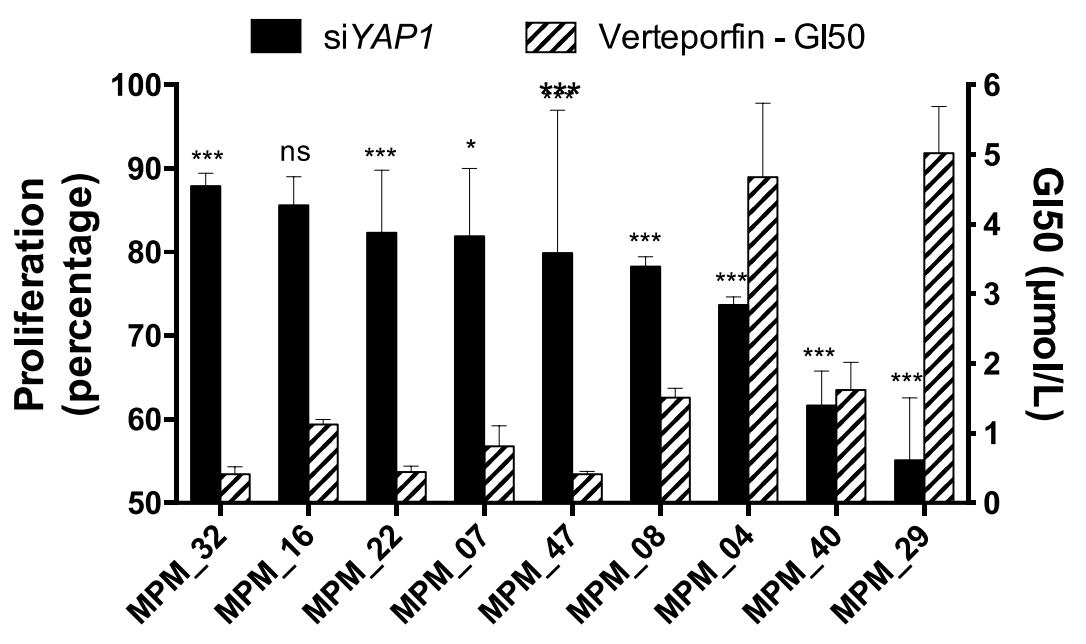

d

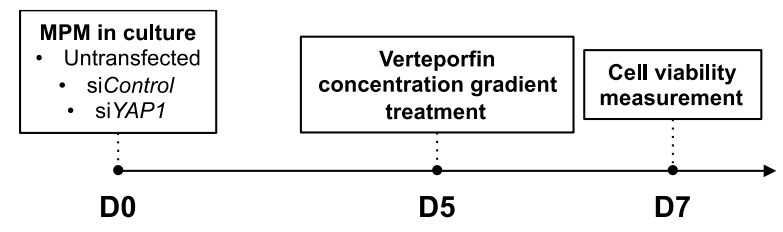

MPM 15

Sensitive MPM in culture

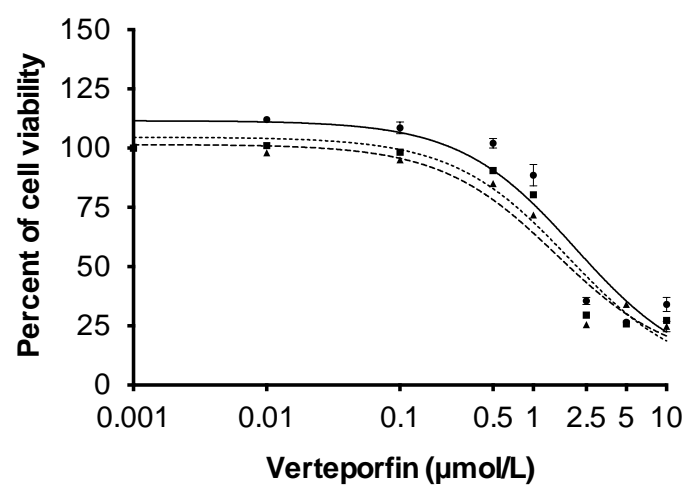

MPM_04

Resistant MPM in culture

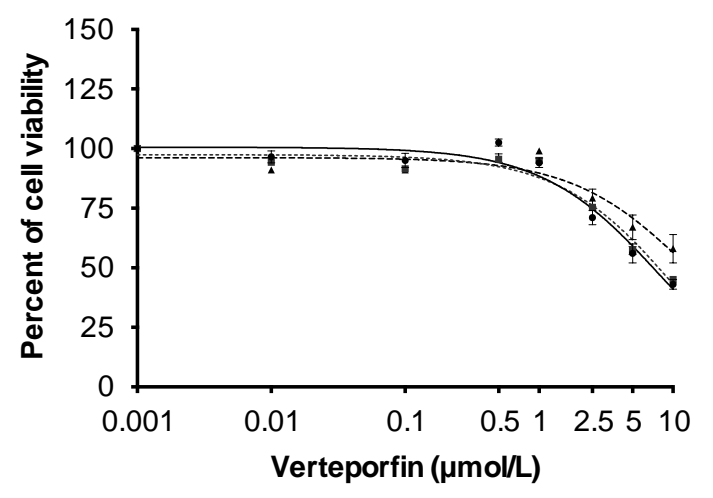




\section{Figure 4}
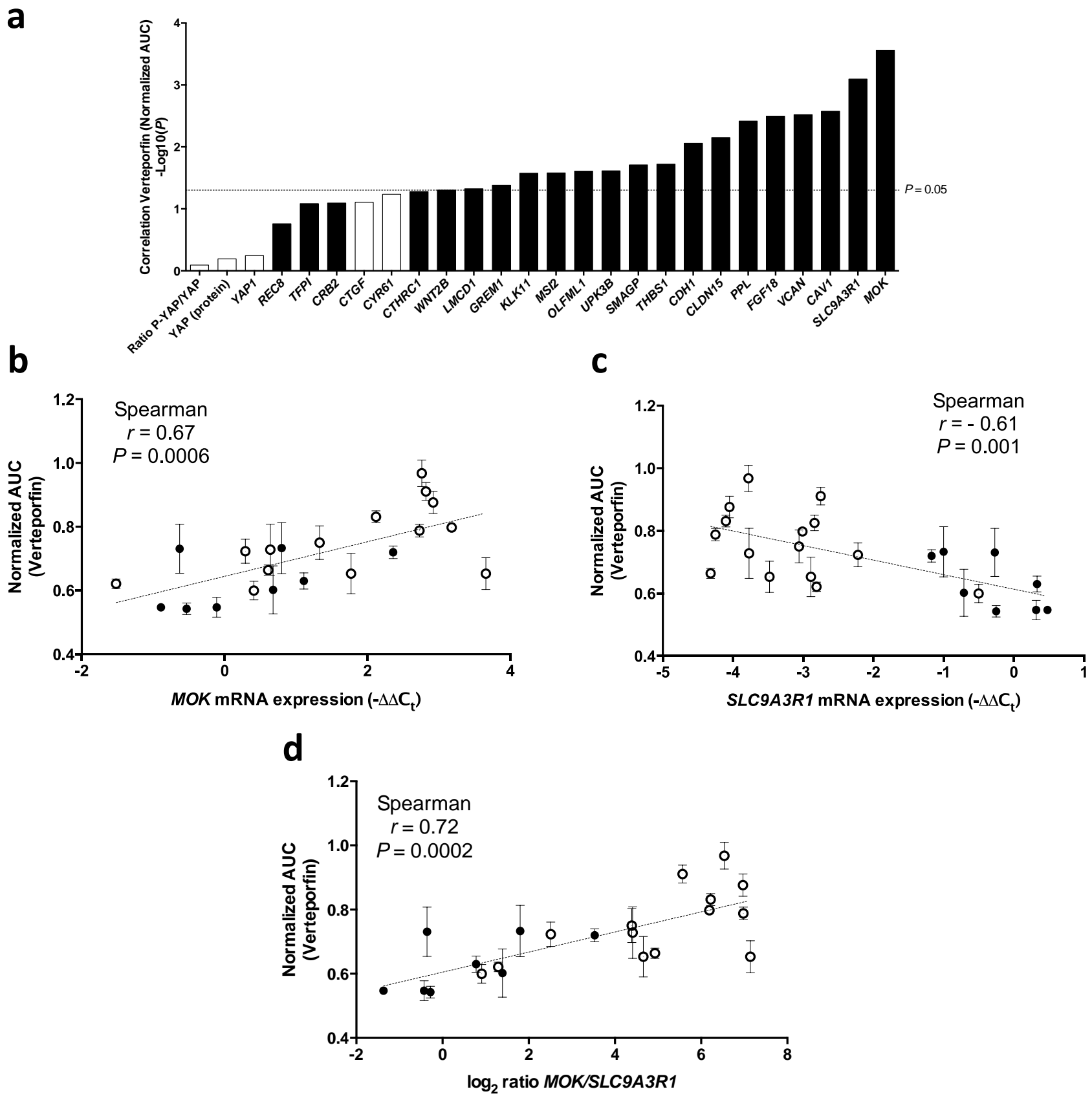


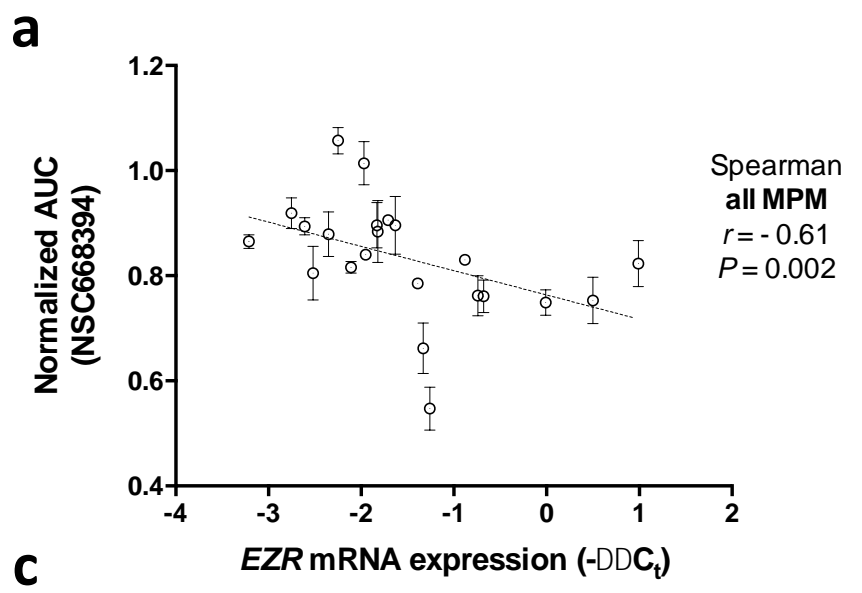

b

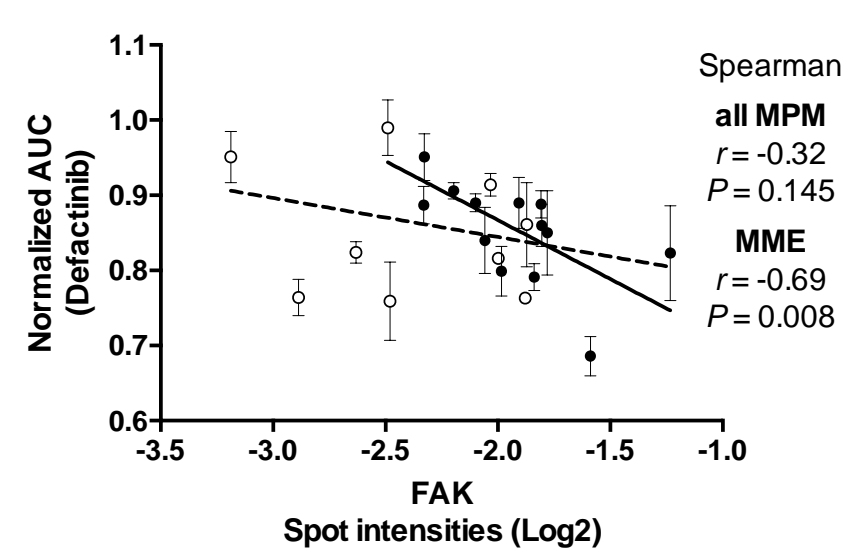

d

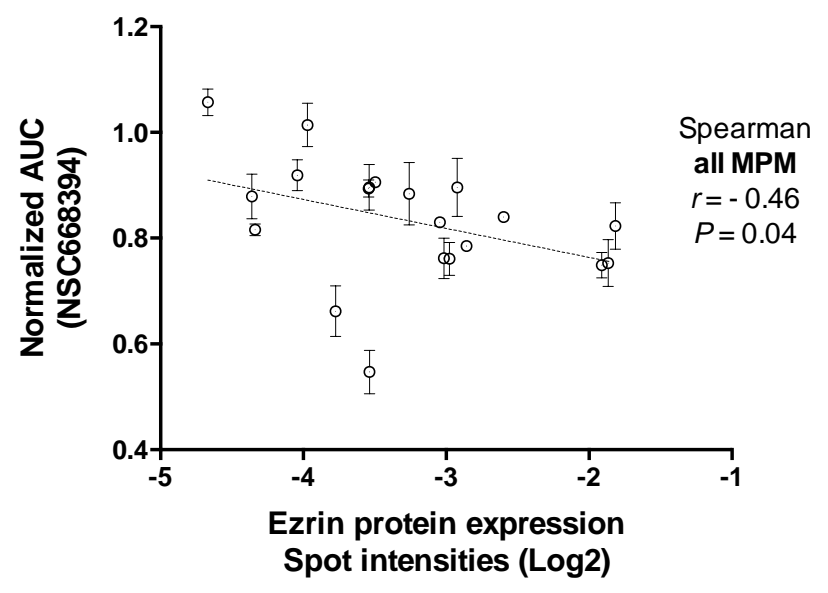

e
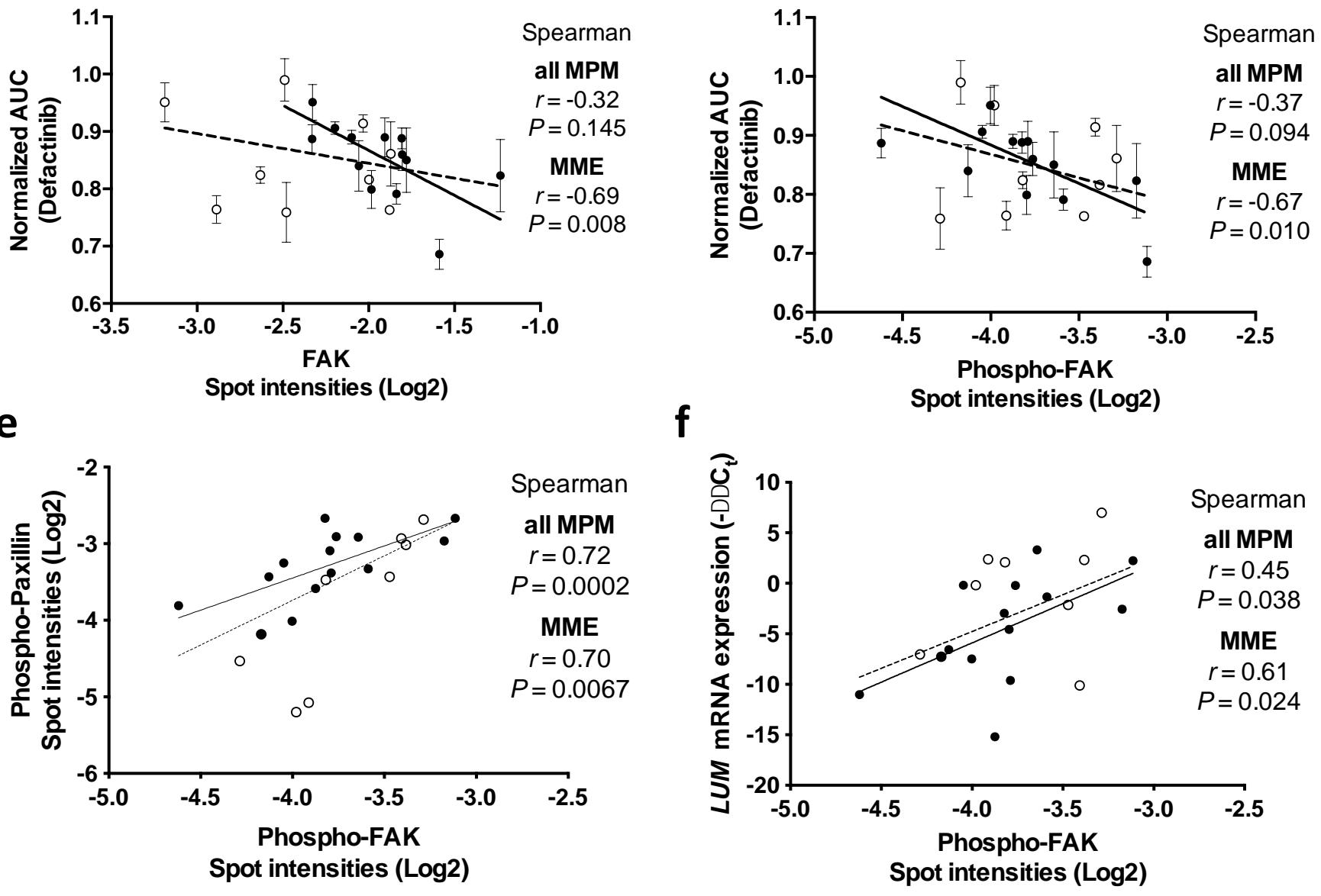

8

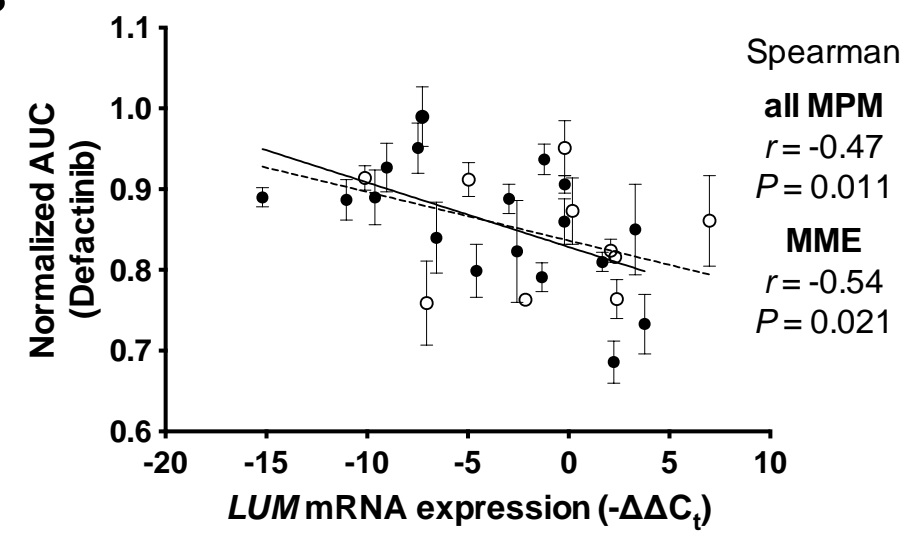

